\title{
Diabetic retinopathy
}

\author{
David A Infeld, John G O’Shea
}

\begin{abstract}
Summary
Diabetic retinopathy is the commonest cause of blindness amongst individuals of working age. The onset of retinopathy is variable. Regular ophthalmic screening is essential in order to detect treatable lesions early. Retinal laser therapy is highly effective in slowing the progression of retinopathy and in preventing blindness. As the sufferers of diabetes mellitus, the commonest endocrine disorder, now constitute approximately $1-2 \%$ of Western populations, concerted multidisciplinary effort must be made towards costeffective community screening by the medical community.
\end{abstract}

Keywords: diabetic retinopathy; diabetes mellitus

\author{
Department of Ophthalmology, \\ University of Birmingham, \\ Birmingham and Midland Eye Centre, \\ Dudley Road, Birmingham B18 7QU, \\ UK \\ DA Infeld \\ JG O'Shea \\ Correspondence to Mr JG O'Shea
}

Accepted 10 June 1997
Diabetes mellitus is the most common cause of blindness amongst the 25-65 year age group. The ocular complications of diabetes include diabetic retinopathy, iris neovascularisation, glaucoma, cataract, and microvascular abnormalities of the optic nerve. The most frequent complication is diabetic retinopathy..$^{1-5}$ The risk of becoming blind increases with the duration of diabetes. The cumulative risk is higher in insulin-dependent diabetes mellitus (IDDM) than in noninsulin dependent diabetes mellitus (NIDDM). ${ }^{14}$ World-wide, it is estimated that over 2.5 million people are blind due to diabetes, which is thus the fourth leading cause of blindness and an increasing problem in developing nations. ${ }^{6}$

Blindness commonly occurs from either macular oedema or ischaemia, vitreous haemorrhage, or tractional retinal detachment. ${ }^{1-5}$ Macular oedema is now the leading cause of loss of vision amongst Western patients. It develops earlier and is more severe in NIDDM than in IDDM..$^{7-9}$ The treatment of macular oedema has therefore been the subject of leading international studies. In these studies, diabetic macular oedema is referred to as clinically significant macular (o)edema (CSME)..$^{7-9}$

\section{Clinical lesions found in diabetic retinopathy ${ }^{1-5}$}

Diabetic retinopathy is primarily a disease of the retinal microvasculature featuring retinal capillary closure, thrombosis, non-perfusion and also capillary leakage. An important pathological event is the loss of capillary pericytes, modified smooth muscle cells, which support the vascular endothelium of the retina.

In IDDM, the vascular changes occur mainly in the mid-peripheral retina. There is retinal ischaemia, release of vasoformative substances and new vessel formation, ie, retinal neovascularisation. ${ }^{1}$ In NIDDM, the vascular changes occur more commonly at the posterior pole. The main pathological changes are due to capillary leakage, micro-aneurysms and macular oedema. ${ }^{1}$ The types of lesions encountered upon fundoscopy include micro-aneurysms, retinal haemorrhages, cotton wool spots, hard exudates, retinal oedema, retinal vein changes, progressing to neovascularisation of the retina and optic disc, and fibrous tissue proliferation.

\section{MICRO-ANEURYSMS}

Retinal micro-aneurysms are focal dilatations of retinal capillaries. They usually occur at the posterior pole, especially temporal to the fovea. They may seem to disappear, only to reappear at the edge of areas of widening capillary non-perfusion.

\section{RETINAL HAEMORRHAGE}

Dot haemorrhages appear as bright red dots and are the same size as large micro-aneurysms. Blot haemorrhages are larger lesions they are typically located within the mid-retina and often correspond with areas of ischaemia. Flame-shaped haemorrhages occur in the nerve fibre layer, more superficially, and are often close to the optic disc. They often absorb slowly after several weeks. Their presence may suggest the co-existence of systemic hypertension.

COTTON WOOL SPOTS

Cotton wool spots are common, especially if the patient is also hypertensive. They occur mostly at the posterior pole and result from occlusion of retinal arterioles with concomitant swelling of local nerve fibre axons due to accumulated axoplasm.

HARD EXUDATES

Hard exudates are yellow deposits of lipid and protein; they occur typically at the posterior pole. 


\section{Clinical classification of diabetic retinopathy ${ }^{1-4}$}

A useful classification according to the types of lesions detected on fundoscopy is as follows:

Mild non-proliferative diabetic retinopathy

- micro-aneurysms

- dot and blot haemorrhages

- hard exudates

Moderate-to-severe non-proliferative diabetic retinopathy

The above lesions plus:

- cotton-wool spots

- venous beading and loops

- intraretinal microvascular abnormalities

Proliferative

- neovascularisation of the retina, optic disc or iris

- fibrous tissue adherent to vitreous face or retina

- tractional retinal detachment

- vitreous haemorrhage

Maculopathy

- macular oedema

- macular haemorrhages or hard exudates

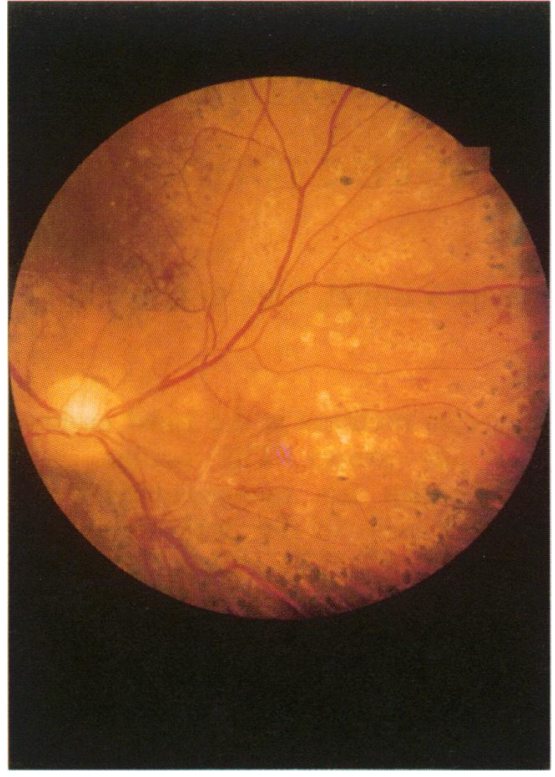

Figure 1 Proliferative diabetic retinopathy. The photograph demonstrates a cluster of new vessels elsewhere on the nasal hemi-retina and discrete areas of chorioretinal atrophy due to panretinal photocoagulation

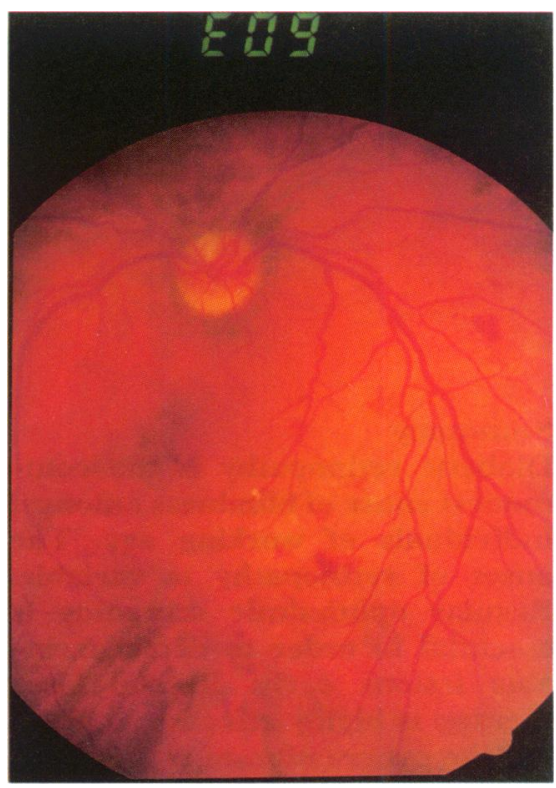

Figure 2 Moderately severe non-proliferative diabetic retinopathy. Blot haemorrhages and micro-aneurysms are prominently featured in this illustration

\section{Box 1}

\section{Diabetic screening}

Screening for diabetic eye problems should include the following:

- the history of any visual symptoms

- measurement of visual acuity (unaided and with spectacles / pinhole if necessary)

- pupil dilatation (tropicamide $1 \%$ drops; the risk of precipitating angle closure glaucoma is very small and, at any rate, this condition is treatable. Patients should be accompanied by a relative and instructed not to drive home.)

- examination of the crystalline lens to detect cataract using the red reflex and the +10 lens setting on the direct ophthalmoscope

- fundus examination

A useful and simple clinical test for the presence of macular oedema is the assessment of visual acuity with a pinhole. In macular oedema the visual acuity is reduced and is not improved with a pinhole ${ }^{7-9}$

Box 2

\section{MACULAR OEDEMA}

Macular oedema is due, inter alia, to leakage from capillaries and microaneurysms. It is very difficult to detect using a direct ophthalmoscope; it is seen as retinal thickening on slit-lamp examination with a diagnostic plano-concave contact lens or +90 dioptre lens. It is may be quite difficult to observe even with these instruments.

\section{SEVERE NON-PROLIFERATIVE RETINOPATHY}

Intraretinal microvascular abnormalities are abnormal, dilated retinal capillaries or may represent intraretinal neovascularisation which has not breached the internal limiting membrane of the retina. Venous beading and intraretinal microvascular abnormalities indicate severe non-proliferative diabetic retinopathy that may rapidly progress to proliferative retinopathy. Venous beading is a sausage-shaped dilatation of the retinal veins. Widespread areas of blot haemorrhages also correspond with retinal non-perfusion.

\section{PROLIFERATIVE RETINOPATHY}

Retinal ischaemia from widespread capillary non-perfusion results in the production of vasoproliferative substances and to the development of intracameral neovascularisation. Neovascularisation can involve the retina, optic disc or the iris (rubeosis iridis). Rubeosis iridis is a sign of severe proliferative disease which may cause intractable glaucoma.

Bleeding from fragile new vessels involving the retina or optic disc can result in vitreous or retinal haemorrhage. Retinal damage can result from persistent vitreous haemorrhage. Pre-retinal haemorrhages are often associated with retinal neovascularisation.

\section{ADVANCED DIABETIC RETINOPATHY}

Contraction of associated fibrous tissue can result in deformation of the macula and tractional retinal detachment. ${ }^{127}$ Such patients may be helped by vitreoretinal surgery including vitrectomy. ${ }^{14}$

\section{Diabetic screening}

Potentially blinding lesions, such as proliferative retinopathy or maculopathy, may develop before the patient notices any visual impairment. ${ }^{14}{ }^{7-9}$ Early treatment with retinal laser photocoagulation slows the progression of diabetic retinopathy; regular screening assessment is therefore imperative (box 2). ${ }^{10-15}$ 


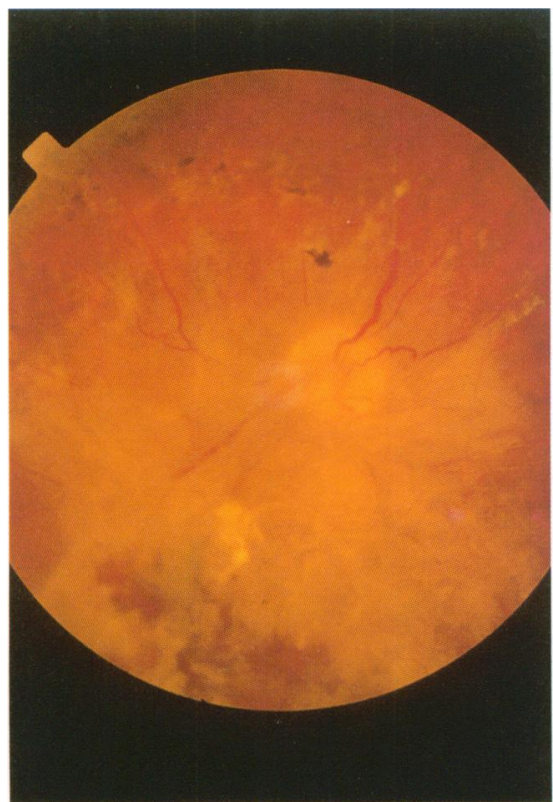

Figure 3 Late manifestations of diabetic retinopathy showing fibrovascular proliferation, here in relation to the optic disc

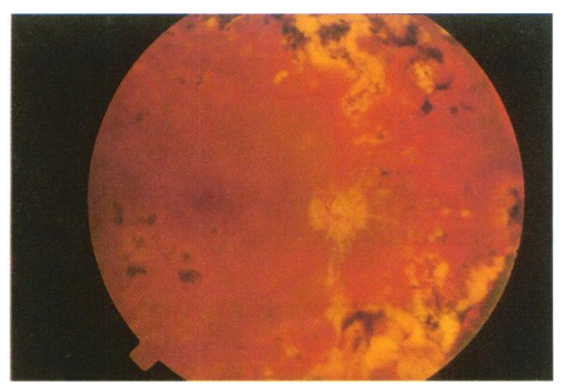

Figure 4 Proliferative diabetic retinopathy. New vessels on the optic disc and discrete areas of chorioretinal atrophy due to laser burns

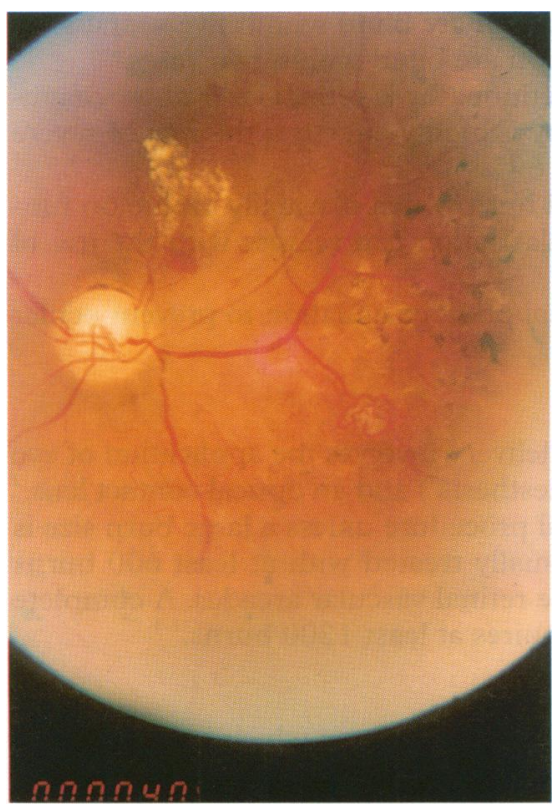

Figure 5 Intraretinal microvascular abnormalities are abnormal dilated retinal capillaries or intraretinal neovascularisation; they are a hallmark of severe non-proliferative diabetic retinopathy and are a precursor of proliferative disease. The photograph also demonstrates blot haemorrhages, hard exudates and laser burns
SLIT LAMP BIOMICROSCOPY

Unfortunately, the direct ophthalmoscope enables adequate examination of only the posterior pole whilst the indirect ophthalmoscope provides insufficient magnification. Slit lamp examination yields much more information by providing stereoscopic assessment of retinal thickening and proliferative retinopathy. It is therefore imperative, to facilitate cost-effective screening, that more practitioners are trained in slit lamp biomicroscopy of the fundus. ${ }^{10-16}$

SUGGESTED FREQUENCY OF SCREENING

NIDDM diabetic patients without retinopathy should be assessed at the time of diagnosis and yearly thereafter. ${ }^{124}$ Screening doctors should look, in particular, for the onset of diabetic macular oedema. ${ }^{14-9}$ Juvenile-onset diabetics (IDDM) rarely develop retinopathy until after eight years of diabetic life. The current recommendation is that screening is unnecessary for at least the first five years of the disease and that patients with mild non-proliferative retinopathy should be screened annually after the onset of puberty until the onset of non-proliferative diabetic retinopathy. ${ }^{14}$ When retinopathy develops, patients should usually be seen annually, if more severe changes develop then screening should be arranged on a three-monthly basis.

Diabetic retinopathy may worsen during pregnancy. Screening should therefore be undertaken at confirmation of pregnancy and every two months during pregnancy, or monthly if retinopathy is present. ${ }^{1{ }^{17}}$ Retinal status should not preclude pregnancy since contemporary methods of management can result in satisfactory retinal and pregnancy outcomes even in the presence of advanced diabetic microvascular disease. ${ }^{1}{ }^{17}$

In summary, patients with IDDM/NIDDM and mild non-proliferative retinopathy should be assessed every 6-12 months by a suitably qualified practitioner, depending on the severity of the disease. The frequency of screening should be increased in special circumstances such as pregnancy, renal failure or other intercurrent illness. ${ }^{1-5}$

\section{Towards cost-effective community screening}

The current consensus of opinion from Europe and the US is that screening for diabetic retinopathy is cost-effective and results in reduced morbidity due to visual disability. ${ }^{18-25}$

An interdisciplinary approach is commonly used. ${ }^{10-12} 2021$ The characteristics of a good screening programme being that the target patients in the community are found and seen at the prescribed intervals, and that the practitioners who conduct the screening have adequate training - that is they must be familiar with the manifestations of diabetic eye disease and with slit lamp biomicroscopy of the fundus. ${ }^{19-24}$

\section{FUNDUS FLUORESCEIN ANGIOGRAPHY}

Additional procedures such as fundus photography and fundus fluorescein angiography are often helpful. ${ }^{1-4}$ The indications for fundus fluorescein angiography include unexplained visual loss, assessing macular pathology and distinguishing the various vascular lesions of diabetic retinopathy. ${ }^{134}$

\section{Lifestyle modification and patient education}

Factors that can worsen diabetic retinopathy and indeed the general prognosis of diabetes, include poor diabetic control, systemic hypertension, hypercholesterolaemia, cigarette smoking, diabetic nephropathy, pregnancy, and cataract surgery. Good diabetic control may slow the development and progression of diabetic retinopathy. ${ }^{1225-30}$ It is of prime importance that the diabetic patient understands the nature of his or her disease and is motivated to cease cigarette smoking and obtain exercise and fastidious control. However, even 'perfect' control is unable to prevent progression of severe diabetic retinopathy. ${ }^{1}$

Systemic hypertension is a common associated finding. It is often secondary to diabetic nephropathy. It is important that hypertension, if present, be controlled as this can slow the progression of diabetic retinopathy. ${ }^{14}$

Diabetic nephropathy accelerates the progression of retinopathy, especially macular oedema, via increased levels of blood pressure, fibrinogen and lipoprotein. The visual prognosis is better if end-stage nephropathy is treated by renal transplantation rather than by dialysis.

Pregnancy may also accelerate the progression of diabetic retinopathy. ${ }^{17}$

Cataract surgery may lead to progression of pre-existing macular oedema and proliferative diabetic retinopathy. However, cataracts may impede fundoscopy 


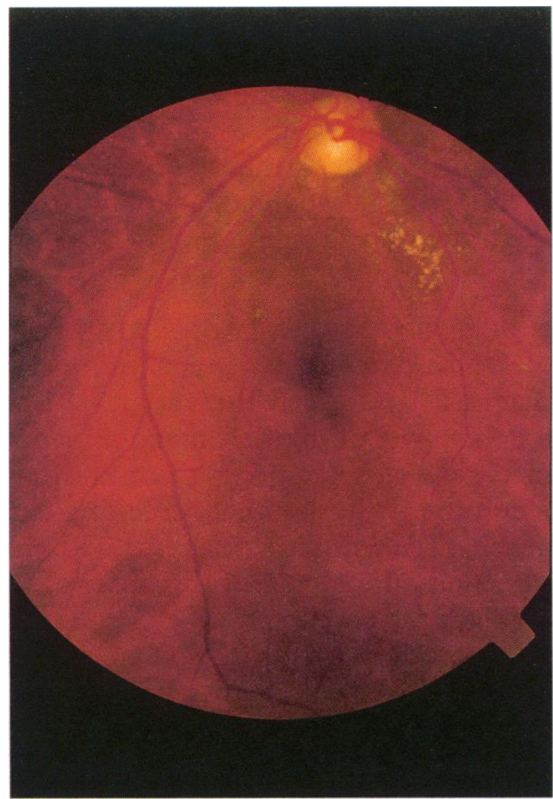

Figure 6 Cotton wool spots and flameshaped haemorrhages indicate that this diabetic patient concurrently suffers from systemic hypertension. Cotton wool spots are common in diabetic retinopathy and result from arteriolar occlusion in the nerve fibre from arteriolar occlusion in the nerve fibre
layer and concurrently accumulated axoplasm

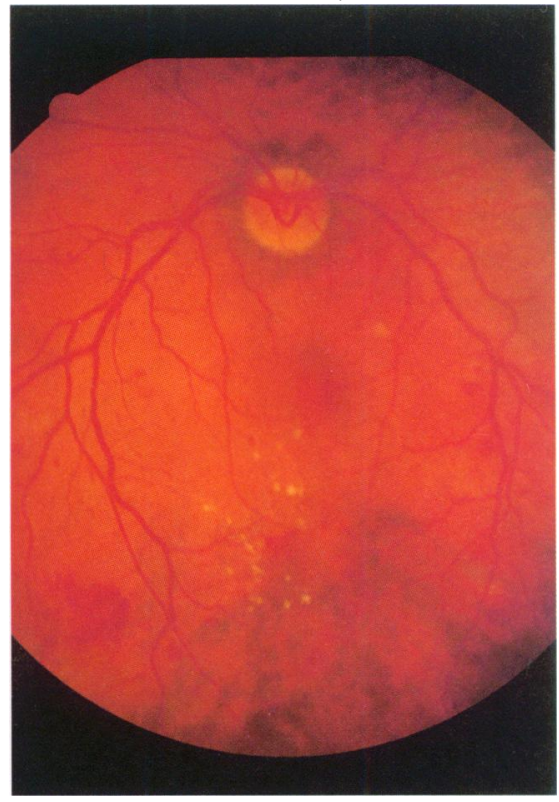

Figure 7 Moderately severe non-proliferative diabetic retinopathy, showing blot haemorrhages, micro-aneurysms and hard exudates. Hard exudes are chiefly composed of lipid residues

\section{Protocol for referring diabetic retinopathy ${ }^{1-5}$ 7-9}

Patients with sight-threatening retinopathy require immediate referral to an ophthalmologist.

Sight-threatening retinopathy is indicated by:

- proliferative diabetic retinopathy, new vessels (neovascularisation) involving the optic disc or the retina

- preretinal haemorrhage

- vitreous haemorrhage

- recent retinal detachment

- rubeosis iridis

Patients should be referred to an ophthalmologist soon if the following lesions are seen during screening examination:

Severe non-proliferative diabetic retinopathy (ie, pre-proliferative retinopathy)

- multiple retinal haemorrhages

- multiple cotton wool spots

- intraretinal microvascular abnormalities, retinal vein beading or retinal vein loops

Non-proliferative retinopathy with macular involvement

- retinal haemorrhages or hard exudates within one disc diameter of the macula

- macular oedema and therefore interfere with the treatment of diabetic retinopathy. If possible, diabetic retinopathy should be treated prior to cataract surgery. ${ }^{12}$

\section{The treatment of diabetic retinopathy - laser photocoagulation}

It is important to note that the patient may in fact have normal visual acuity yet meet the criteria for urgent laser therapy. ${ }^{14}$

\section{PROLIFERATIVE RETINOPATHY}

Proliferative retinopathy has a very poor prognosis if untreated. If untreated, $50 \%$ of patients with retinal neovascularisation are blind within five years; $50 \%$ of patients with optic disc neovascularisation are blind within two years. ${ }^{1-4}$

The mainstay of treatment of diabetic retinopathy is retinal laser photocoagulation, an ablative treatment. Laser therapy is highly effective; the rate of severe visual loss at two years can be reduced by $60 \% .^{14}{ }^{7-9}$

Laser photocoagulation causes a retinal burn which is usually visible on fundoscopy. Retinal and optic disc neovascularisation can regress with the use of retinal laser photocoagulation. ${ }^{124}$

Rubeosis iridis requires urgent panretinal photocoagulation to prevent ocular pain and blindness from glaucoma. ${ }^{34}$

\section{OPERATIVE TECHNIQUE}

The technique of laser photocoagulation delivery involves the application of eye drops (for pupil dilatation and corneal anaesthesia ) and an optical contact lens. ${ }^{2}$ Photocoagulation is generally not a painful procedure unless a large burn size is made. Mild proliferative retinopathy is usually treated with at least 600 burns placed between the retinal equator and the retinal vascular arcades. A complete panretinal photocoagulation treatment requires at least 1200 burns. $^{1-4}$

\section{MACULAR LASER GRID FOR MACULAR OEDEMA}

The indications for laser therapy include macular oedema which is now treated with a macular laser grid. Early referral and detection of disease is important, as treatment of maculopathy is far more successful if undertaken at an early stage of the disease process. Macular laser photocoagulation reduces the rate of loss of vision from macular oedema by $50 \%$ at two years. Leaking macular micro-aneurysms can be sealed directly with laser energy. ${ }^{7-9}$ 


\section{Support for the visually disabled}

Royal National Institute for the Blind

224 Great Portland Street,

London W1N 6AA, UK

Tel 01713881266

(Handout on facilities available

0345-023153)

Partially Sighted Society

PO Box 322, Queens Rd, Doncaster

DN1 2NX, UK

Tel 01302 323132/0171 3721551

\section{Box 4}

1 Hamilton AMP, Ulbig MW, Polkinghorne P. Management of diabetic retinopathy. London: BMJ Publishing Group, 1996.

2 Kanski JJ. Clinical ophthalmology, 3rd edn. London: Butterworth-Heinemann, 1994; pp London:

3 Kohner EM. Diabetic retinopathy. BMF 1993; 307:1195-9.

4 American Academy of Ophthalmology. Diabetic retinopathy - preferred practice. San Francisco: American Academy of Ophthalmology Press. 1993.

5 Ai E. Current management of diabetic retinopathy. West f Med 1992;157:67-70.

6 Foster A. World distribution of blindness. $f$ Commun Eye Health 1988;1:2-3.

7 Ulbig MW, McHugh DA, Hamilton AMP. Diode laser photocoagulation for diabetic retinopathy. Br f Ophthalmol 1995;79:318-21.

8 Ferris FL, Podgor MJ, Davis MD. ETDRS Research Group Report No 1. Photocoagulation for diabetic macular oedema. Arch Ophthaltion for diabetic macular

9 Ferris FL, Podgor MJ, Davis MD. The Diabetic Research Group Report No 12. Macular edema in diabetic retinopathy study patients. Ophthalmology 1987;94:754-60.

10 Gatling W, Howie AJ, Hill RD. An optical practice based diabetic eye screening programme. Diabet Med 1995;12:531-6.

11 Duenas MR. Diabetes and optometry. $f \mathrm{Am}$ Optom Assoc 1994;65:545-6.

12 Alexander LJ, Duenas MR. Eye care for patients with diabetes in the state of Florida: status in 1988. F Am Optom Assoc 1994;65:552-8.
RISKS AND COMPLICATIONS OF LASER PHOTOCOAGULATION

Although laser therapy can be highly effective in preventing blindness, it is associated with occasional complications. ${ }^{134}$ Retinal vein occlusion can follow inadvertent photocoagulation of a retinal vein. Rarely, there may be loss of central acuity from inadvertent photocoagulation of the fovea. Vitreous haemorrhage can follow photocoagulation of retinal or choroidal vessels. Blurred vision may result from glare, reflected laser light within the eye, macular oedema or iritis. There may be visual field restriction, impaired night vision or impaired colour vision. Visual field constriction may impair fitness to drive, although ophthalmologists now increasingly strive to avoid this most undesirable problem. The Estermann Binocular field programme is used in conjunction with computerised perimetry to asses DVLA criteria for fitness to drive.

Headache can follow laser therapy. The headache is usually relieved with rest and simple analgesia. Glaucoma must be excluded if the headache is severe or persistent. $^{134}$

13 Bischoff P, Ophthalmologische Verlaufskontrollen bei der diabetischen Retinopathie. Klin Monatsbl Augenheilkd 1993;202:443-6.

14 Flanagan D. Screening for diabetic retinopathy. Practitioner 1994;238:37-42.

15 Hendrikse F. Consensus over diagnose, screening en behandeling van diabetische retinopathie. [Consensus over diagnosis, screening and treatment of diabetic retinopathy] Ned Tijdschr Geneeskd 1992;136:1706-9.

16 Dunbar MT. Co-management of patients with diabetes. Optom Clin 1994;4:43-62.

17 Reece EA, Lockwood CJ, Tuck S, et al. Retinal and pregnancy outcomes in the presence of diabetic proliferative retinopathy. $\mathcal{F}$ Reprod $\mathrm{Med}$ 1994;39:799-804

18 Javitt JC, Aiello LP. Cost-effectiveness of detecting and treating diabetic retinopathy. Ann Intern Med 1996;124:164-9.

19 Chen CJ, Herring J, Chen AS. Managing diabetic retinopathy: the partnership between ophthalmologist and primary care physician. $\mathcal{J}$ Miss State Med Assoc 1995;36:201-8.

20 Yung CW, Boyer MM, Marrero DG, Gavin TC. Patterns of diabetic eye care by primary care physicians in the state of Indiana. Ophthal Epidemiol 1995;2:85-91.

21 Drummond MF, Davies LM, Ferris FL. Assessing the costs and benefits of medical research: the diabetic retinopathy study. Soc Sci Med 1992;34:973-81.

22 Muhlhauser I, Sulzer M, Berger M Quality assessment of diabetes care according to the recommendations of the St Vincent Declaration: a population-based study in a rural area of Austria. Diabetologia 1992;35:429-35.

23 Fendrick AM, Javitt JC, Chiang YP. Costeffectiveness of the screening and treatment of effectiveness of the screening and treatment of
diabetic retinopathy. What are the costs of underutilization? Int $f$ Technol Assess Health Care 1992;8:694-707.

24 Ferris FL. Diabetic retinopathy. Diabet Care 1993;16:322-5.

25 Diabetes Control and Complications Trial Research Group. Effect of intensive diabetes treatment on the development and progression of long-term complications in adolescents with insulin-dependent diabetes mellitus: Diabetes Control and Complications Trial. $\mathcal{f}$ Pediat 1994;125:177-88.

26 Parnes RE, Singerman LJ. Diabetic retinopathy. Preserving your patients' sight. F Fla Med Assoc 1994;81:236-9.

27 Blom ML, Green WR, Schachat AP. Diabetic retinopathy: a review. Del Med $\Im$ 1994; 66:379_

28 Wolfsdorf JI, Laffel LM. Diabetes in childhood: predicting the future. Pediatr Ann 1994;23:306-

29 Ilarde A, Tuck M. Treatment of non-insulindependent diabetes mellitus and its complications. A state of the art review. Drugs Aging 1994;4:470-91.

30 Ferris FL. Results of 20 years of research on the treatment of diabetic retinopathy. Prev Med 1994;23:740-2. 